\title{
ОСОБЕННОСТИ ЛИЧНОСТИ И СИСТЕМЫ ЗНАЧИМЫХ ОТНОШЕНИЙ МАТЕРЕЙ ДЕЛИНКВЕНТНЫХ ПОДРОСТКОВ
}

\author{
(С) Беляева С.И., Щелкова О.Ю.
}

\author{
Кафедра медицинской психологии и психофизиологии \\ Санкт-Петербургского государственного университета, Санкт-Петербург \\ E-mail: belyaevasveta@,inbox.ru
}

\begin{abstract}
В статье приводятся результаты исследования индивидуально-личностных и психосоциальных характеристик матерей делинквентных подростков $(\mathrm{n}=76$, средний возраст - $\mathrm{M}=38,12 \pm 0,50)$ в сопоставлении с соответствующими характеристиками матерей подростков с нормативным поведением $(\mathrm{n}=76$, средний возраст - $\mathrm{M}=37,97 \pm 0,46)$, а также особенности системы значимых отношений (отношение к собственной личности, к своему здоровью, к детям, родительским семьями, к собственным супружескими отношениями, к своей трудовой деятельности и досугу) в сопоставляемых группах женщин. Приводятся результаты эмпирического исследования особенностей взаимодействия матерей и их детей-подростков в процессе совместной деятельности (авторская экспериментальная техника «Совместное рисование матери и ее ребенка-подростка»). Представлены практические рекомендации по индивидуальной поддерживающей психотерапии матерей трудных подростков, находящихся в ситуации хронического эмоционального напряжения, а также рекомендации по проведению семейной психотерапии в их семьях.
\end{abstract}

Ключевые слова: делинквентные подростки, матери, система отношений, самопринятие, уровень субъективного контроля личности, взаимодействие матери и подростка, совместное рисование.

\section{PERSONAL PECULIARITIES AND CHARACTERISTICS OF MEANINGFUL ATTITUDINAL SYSTEM OF DELINQUENT TEENAGERS' MOTHERS \\ Belyaeva S.I., Shchelkova O.Yu.}

Department of Medical Psychology and Psychophysiology of Saint-Petersburg State University, St. Petersburg

The article presents the results of the study of individual-personal and psychosocial characteristics of delinquent teenagers' mothers $(\mathrm{n}=76$, mean age $-\mathrm{M}=38.12 \pm 0.50)$ compared with the corresponding characteristics of mothers of teenagers with rules-based behavior ( $n=76$, mean age $-M=37.97 \pm 0.46)$, as well as peculiarities of the system of meaningful attitudes (self-concept, attitude to their health, children, parents' families, to their own marital relationships, to their work and leisure) in the compared groups of women. The article also presents the results of the empirical study of interaction between mothers and their teenage children in the process of joint activity (the author's experimental technique "Joint drawing of a mother and her teenage child"). The practical recommendations for individual supportive psychotherapy of delinquent teenagers' mothers, who are in situation of chronic emotional stress, as well as the recommendations for family psychotherapy in their families were given.

Keywords: delinquent teenagers, mothers, attitudinal system, self-concept, level of the personal subjective control, interaction of a mother and a teenager, co-drawing.

В настоящее время психологи разных теоретических ориентаций сходятся в признании патогенного влияния нарушенных внутрисемейных отношений на психическое и нравственное развитие личности ребенка $[1,5,10,12,14,17,19,20$, $21,22,24,25,27]$. Согласно многочисленным психологическим исследованиям психосоциальные нарушения в семье негативно влияют на стиль родительского воспитания, создают психотравмирующую ситуацию, что снижает адаптивные возможности подростка, делая его более склонным к противоправному поведению $[2,6,7$, $9,15,18,23,26,28]$. При этом в нашей стране не существует официально утвержденных программ психологической помощи семьям подростков с делинквентным поведением.

Очевидная потребность в научно обоснованном подходе к организации и проведению профилактической работы с несовершеннолетними пра- вонарушителями и их семьями, основанной на психологической диагностике и ориентированной на своевременную адекватную психологическую помощь, определяет актуальность изучения психосоциальных и индивидуально-психологических особенностей матерей делинкветных подростков с противоправным поведением, часто являющихся единственным родителем в семье, и разработки практических рекомендаций по психопрофилактической работе с ними.

Цель исследования: изучить индивидуальнопсихологические особенности, а также наиболее значимые сферы отношений матерей подростков с делинквентным поведением.

Задачи исследования:

1. Изучить психосоциальные характеристики и наиболее значимые сферы отношений матерей и их детей-подростков с делинквентным поведением. 
2. Изучить особенности Я-концепции и уровень интернальности матерей подростков с делинквентным поведением.

3. Изучить особенности взаимодействия (эмоциональный контакт, взаимопонимание, поведенческие характеристики) матери и ребенка в процессе выполнения совместной деятельности в группах социально адаптированных и делинквентных подростков.

4. Разработать практические рекомендации по психопрофилактической работе с семьями подростков-правонарушителей.

Гипотезы исследования:

1. Существуют различия между психосоциальными характеристиками матерей делинквентных и социально адаптированных подростков.

2. Существуют особенности взаимодействия матери и ребенка в процессе выполнения совместной деятельности в группе матерей и подростков с делинквентным поведением по сравнению с группой матерей и подростков с нормативным поведением.

\section{МАТЕРИАЛЫ И МЕТОДЫ ИССЛЕДОВАНИЯ}

Материалом исследования явились данные психологического исследования 152 матерей старшеклассников шести муниципальных образовательных учреждений (ОУ) г. Норильска Красноярского края и 152 их ребенка-подростка. Из них 76 подростков посредством экспертной оценки психологов, социальных педагогов и классных руководителей ОУ были определены как социально адаптированные, и 76 - как делинквентные, поставленные в период исследования на учет в комиссии по делам несовершеннолетних и защите их прав (КДН и ЗП) за совершенные ими правонарушения. Всего исследовано 304 человека. От всех участников было получено устное информированное согласие на проведение психологического исследования.

Исследованы женщины - матери подростков с делинквентным поведением в возрасте от 29 до 49 лет $(\mathrm{M}=38,12 \pm 0,50)$, матери подростков $\mathrm{c}$ нормативным поведением в возрасте от 32 до 51 года $(\mathrm{M}=37,97 \pm 0,46)$, а также их детиподростки с делинквентным (48 мальчиков и 28 девочек) и нормативным (38 мальчиков и 38 девочек) поведением в возрасте от 14 до 16 лет ( $\mathrm{M}=14,95 \pm 0,09$ и $\mathrm{M}=15,07 \pm 0,08$ соответственно).

Для реализации цели и задач исследования использовались клинико-психологический, экспериментально-психологический и математикостатистический методы. Клинико-психологический метод включал специально разработанное полуструктурированное интервью. В сопоставляемых группах исследованных женщин и их детей-подростков с делинквентным и нормативным поведением были изучены социально-демографические характеристики; особенности их образа жизни, включая семейные отношения (в т.ч. с прародительской семьей); трудовую (учебную) деятельность, особенности досуга, состояние здоровья, употребление табака, алкоголя и наркотических средств; зоны наибольшей неудовлетворенности собственным психосоциальным статусом. Отдельный блок интервью составили вопросы к матери, касающиеся особенностей раннего развития ее ребенка и актуальных взаимоотношений с ним. Также была изучена соцально-педагогическая информация: социальные паспорта семей, банк данных детей и подростков, состоящих на учете в группе по делам несовершеннолетних, банк данных семей, находящихся в социально опасном положении. Всего авторское интервью содержит 75 пунктов.

Экспериментально-психологический метод представлен комплексом психометрических процедур: «Личностный дифференциал» (ЛД) [8], «Уровень субъективного контроля» (УСК) [11], а также модифицированной авторами экспериментальной техникой «Совместное рисование матери и ее ребенка-подростка» [16].

Для сопоставления результатов исследования в группах матерей и социально адаптированных и делинквентных подростков различия частот (номинативные данные) вычислялись по критерию $\chi^{2}$ Пирсона, различия средних показателей - по $t$-критерию Стьюдента. Вычисления производились с помощью статистического программного пакета SPSS.

Основные этапы исследования: 1) беседы с социальным педагогом, психологом и классными руководителями образовательного учреждения $(\mathrm{OУ}) ; 2$ ) беседа с медицинским работником ОУ; 3) индивидуальная беседа и психологическое исследование подростка; 4) индивидуальная беседа и психологическое исследование матери; 5) выполнение совместного рисунка матерью и подростком.

В ходе анализа результатов исследования были обнаружены сходные показатели по ряду изученных психосоциальных и личностных характеристик матерей и их детей-подростков [3]. В настоящей публикации представлены данные, полученные при сопоставлении части результатов комплексного психологического исследования, отражающие особенности системы отношений матерей подростков с делинквентным поведением. При анализе материалов использован системный подход. Личность матери понимается как система отношений [13]; родительское отношение 
матери - как многомерное корригируемое образование [4]. В связи с этим в настоящей работе психосоциальные и индивидуально-личностные характеристики матерей делинквентных подростков представлены в контексте отношения исследованных женщин к собственной личности, к своему здоровью, к детям, родительским семьям, супружеским отношениям, к трудовой деятельности и досугу.

\section{РЕЗУЛЬТАТЫ ИССЛЕДОВАНИЯ И ИХ ОБСУЖДЕНИЕ}

Сравнительный анализ показателей психосоциальных характеристик матерей подростков с делинквентным и нормативным поведением, полученных с помощью специально разработанного клинико-психологического интервью, показал, что матери делинквентных подростков, в сравнении с матерями социально адаптированных подростков, чаще не удовлетворены своим трудоустройством $\quad(26,3 \%$ и $0 \%$ соответственно; $\mathrm{p}<0,001)$, взаимоотношениями в семье $(61,9 \%$ и $0 \%$ соответственно; $\mathrm{p}<0,001)$ и собственной жизнью в целом $(59,2 \%$ и $0 \%$ соответственно; $\mathrm{p}<0,001)$, не имеют увлечений, хобби $(68,4 \%$ и $5,3 \%$ соответственно; $\mathrm{p}<0,001)$ и поддержки со стороны своей семьи $(44,7 \%$ и $0 \%$ соответственно; $<<0,001)$; как «плохие» охарактеризовали отношения с мужем 21,1\% и 2,6\% матерей соответственно $(\mathrm{p}<0,001)$.

Изучение отношений матерей подростков с делинквентным и нормативным поведением к их родительским семьям показало, что у матерей подростков с делинквентным поведением в срав- нении с сопоставляемой группой чаще встречаются не только структурные нарушения в их родительских семьях (59,2\% и $25 \%$ соответственно; $\mathrm{p}<0,001)$, но и нарушения взаимоотношений с родителями, связанные с отсутствием психологической поддержки (46,1\% и 2,6\% соответственно; $\mathrm{p}<0,001)$, и низкой степенью их позитивного участия (34,2\% и $0 \%$ соответственно; $\mathrm{p}<0,001)$.

Анализ актуального отношения матерей к своим детям выявил, что матери подростков с делинквентным поведением чаще, чем матери социально адаптированных подростков, говорят об отсутствии взаимопонимания $(34,2 \%$ и $0 \%$ соответственно; $\mathrm{p}<0,001)$ и доверия $(36,8 \%$ и $0 \%$ соответственно; $\mathbf{p}<0,001)$, редко или почти никогда не проводят время со своими детьми-подростками (76,2\% и 1,3\% соответственно; $\mathrm{p}<0,001)$, мотивируя это тем, что они уже взрослые, и у них свои интересы; применяют физические наказания (59,2\% и 2,6\% соответственно; $\mathrm{p}<0,001)$.

Матери делинквентных подростков чаще, чем женщины сопоставляемой группы, давали оценку состояния своего здоровья как «не очень хорошего» $(43,4 \%$ и 22,4\% соответственно; $\mathrm{p}<0,001)$ и «Плохого» $(15,8 \%$ и $0 \%$ соответственно; $\mathrm{p}<0,001)$.

Таким образом, результаты клинико-психологического исследования показывают, что удовлетворенность качеством собственной жизни: состоянием здоровья, актуальными условиями жизни - работой, проведением досуга, взаимоотношениями в родительской и собственной семье, в том числе, взаимоотношениями со своими детьмиподростками, в группе матерей делинквентных подростков чаще существенно ниже, чем в группе матерей подростков с нормативным поведением.

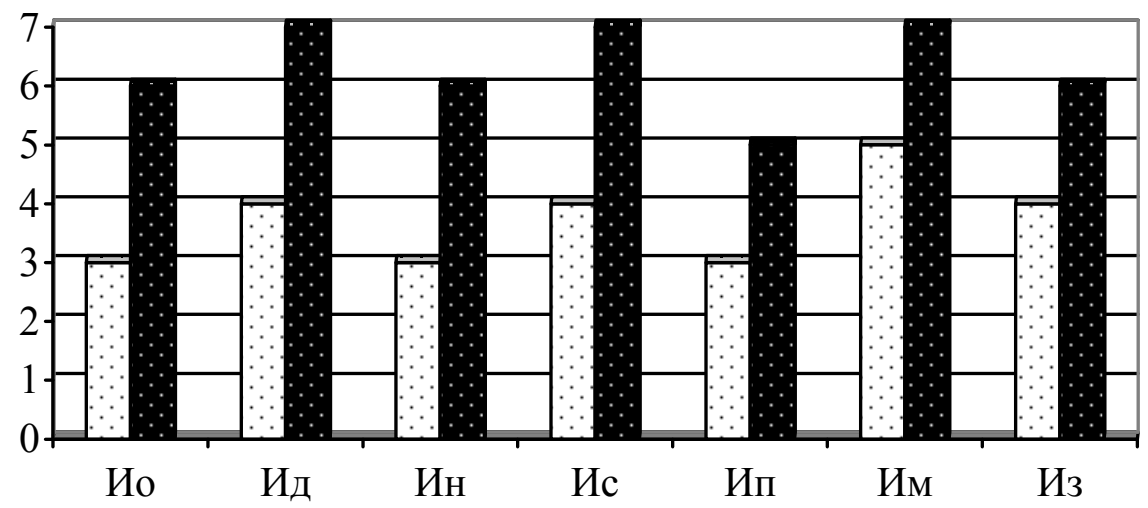

$\square$ матери подростков с делинквентным поведением

матери подростков с нормативным поведением

Рис. 1. Сравнительные показатели уровня интернальности (в стенах) матерей подростков с делинквентным и нормативным поведением.

Примечание: в методике УСК показатель 5,5 стен соответствует среднему (нормальному) уровню субъективного контроля личности; показатели ниже 5 стен - низкому уровню; показатели выше 6 стен - высокому уровню субъективного контроля личности. Чем выше показатель, тем более выражена интернальность личности [Бажин Е.Ф. с соавт., 1984]. Эти нормативы распространяются как на общий уровень интернальности (ИО), так и на проявления интернальности в области достижений (Ид) и неудач (Ин), семейных (Ис), производственных (Ип) и межличностных отношений (Им), в отношении здоровья и болезни (Из). 
Таблица 1

Сопоставление средних оценок факторов ЛД, отражающих особенности восприятия собственной личности матерями подростков с делинквентным и нормативным поведением

\begin{tabular}{|c|c|c|c|c|c|}
\hline \multirow{3}{*}{$\begin{array}{c}\text { Факторы } \\
\text { методики ЛД }\end{array}$} & \multicolumn{2}{|c|}{$\begin{array}{c}\text { Матери } \\
\text { подростков с делинквентным } \\
\text { поведением }\end{array}$} & \multicolumn{2}{|c|}{$\begin{array}{c}\text { Матери } \\
\text { подростков с нормативным } \\
\text { поведением }\end{array}$} & \multirow{3}{*}{$\begin{array}{c}\text { Достоверные } \\
\text { различия }\end{array}$} \\
\hline & $\begin{array}{c}\text { Я-реальное } \\
\text { A }\end{array}$ & $\begin{array}{c}\text { Я-идеальное } \\
\text { В }\end{array}$ & $\begin{array}{c}\text { Я-реальное } \\
\text { С }\end{array}$ & $\begin{array}{c}\text { Я-идеальное } \\
\text { D }\end{array}$ & \\
\hline & $\mathrm{M} \pm \mathrm{m} \quad \mathrm{n}=76$ & $\mathrm{M} \pm \mathrm{m} \quad \mathrm{n}=76$ & $\mathrm{M} \pm \mathrm{m} \quad \mathrm{n}=76$ & $\mathrm{M} \pm \mathrm{m} \quad \mathrm{n}=76$ & \\
\hline Оценка & $1,6 \pm 0,10$ & $2,5 \pm 0,07$ & $2,2 \pm 0,05$ & $2,5 \pm 0,05$ & $\begin{array}{c}\mathrm{AC}^{* * * *} \\
\mathrm{AB}^{* * *} \mathrm{CD}^{*}\end{array}$ \\
\hline Сила & $0,6 \pm 0,10$ & $1,9 \pm 0,07$ & $1,2 \pm 0,07$ & $1,5 \pm 0,06$ & $\begin{array}{l}\mathrm{AC}^{* * *} \mathrm{BD}^{* * *} \\
\mathrm{AB} * * * \mathrm{CD}^{*}\end{array}$ \\
\hline Активность & $1,3 \pm 0,08$ & $1,4 \pm 0,08$ & $1,7 \pm 0,07$ & $1,6 \pm 0,07$ & $\mathrm{AC}^{* *} \quad \mathrm{BD}^{*}$ \\
\hline
\end{tabular}

Примечание: ***-p<0,001; ** $-\mathrm{p}<0,01 ; *-\mathrm{p}<0,05$.

Таблица 2

Сопоставление средних оценок факторов ЛД, отражающих особенности восприятия личности ребенка матерями подростков с делинквентным и нормативным поведением

\begin{tabular}{|c|c|c|c|c|c|}
\hline \multirow{3}{*}{$\begin{array}{c}\text { Факторы методики } \\
\text { «Личностный } \\
\text { дифференциал» }\end{array}$} & \multicolumn{2}{|c|}{$\begin{array}{c}\text { Матери подростков с } \\
\text { делинквентным поведением }\end{array}$} & \multicolumn{2}{|c|}{$\begin{array}{c}\text { Матери подростков с } \\
\text { нормативным поведением }\end{array}$} & \multirow{3}{*}{$\begin{array}{c}\text { Достоверные } \\
\text { различия }\end{array}$} \\
\hline & $\begin{array}{l}\text { Ребенок- } \\
\text { реальное } \\
\text { А }\end{array}$ & $\begin{array}{c}\text { Ребенок- } \\
\text { идеальное } \\
\text { В }\end{array}$ & $\begin{array}{l}\text { Ребенок- } \\
\text { реальное } \\
\text { С }\end{array}$ & $\begin{array}{c}\text { Ребенок- } \\
\text { идеальное } \\
\text { D }\end{array}$ & \\
\hline & $\mathrm{M} \pm \mathrm{m} \quad \mathrm{n}=76$ & $\mathrm{M} \pm \mathrm{m} \quad \mathrm{n}=76$ & $\mathrm{M} \pm \mathrm{m} \quad \mathrm{n}=76$ & $\mathrm{M} \pm \mathrm{m} \quad \mathrm{n}=76$ & \\
\hline Оценка & $0,4 \pm 0,10$ & $2,7 \pm 0,05$ & $2,2 \pm 0,06$ & $2,6 \pm 0,05$ & $\begin{array}{c}\mathrm{AC}^{* * *} \mathrm{AB}^{* * * *} \\
\mathrm{CD}^{* * *}\end{array}$ \\
\hline Сила & $0,8 \pm 0,12$ & $1,3 \pm 0,07$ & $1,4 \pm 0,07$ & $1,7 \pm 0,05$ & $\begin{array}{l}\mathrm{AC}^{* * *} \mathrm{BD}^{* *} \\
\mathrm{AB}^{* * *} \mathrm{CD}^{* * * *}\end{array}$ \\
\hline Активность & $1,5 \pm 0,10$ & $0,8 \pm 0,08$ & $1,3 \pm 0,07$ & $1,4 \pm 0,05$ & $\begin{array}{l}\mathrm{AC}^{*} \mathrm{BD}^{* * * *} \\
\mathrm{AB}^{* * *} \mathrm{CD}^{*}\end{array}$ \\
\hline
\end{tabular}

Примечание: $* * *-\mathrm{p}<0,001 ; * *-\mathrm{p}<0,01 ; *-\mathrm{p}<0,05$.

Результаты психодиагностического исследования личностных характеристик матерей подростков с делинквентным и нормативным поведением показали, что в группе матерей делинквентных подростков все показатели уровня субъективного контроля ниже, чем у матерей социально адаптированных подростков $(\mathrm{p}<0,001)$. Анализ структуры интернальности определил особо низкие значения показателей общей интернальности (M=-0,8 $\pm 2,4 ; 3$ стена), интернальности в области неудач (M=-2, $0 \pm 0,7 ; 3$ стена) и в области производственных отношений $(\mathrm{M}=0,9 \pm 0,6 ; 3$ стена; рис. 1).

Такие показатели субъективного контроля личности матерей делинквентных подростков позволяют сделать предположение об их субъективной неспособности проявлять ответственность за то, как складывается их жизнь в целом, и производственные отношения, в частности; нести ответственность за собственные неудачи; влиять на конкретные события собственной жизни.
Изучение особенностей восприятия собственной личности матерями делинквентных подростков посредством методики «Личностный дифференциал» (ЛД) позволило определить значения трех основных факторов восприятия себя исследованными женщинами (Я-реальное) - Оценки, Силы, Активности, в соотношении с представлениями об образе Я-идеальное (таблица 1).

Данные, приведенные в таблице 1 , показывают, что в группах матерей подростков с адаптивным и делинквентным поведением обнаружены статистически значимые различия по факторам Оценка, Сила, Активность Я-реального. Также обнаружены различия в образах Я-идеального: матери подростков с делинквентным поведением в идеале хотели бы быть более сильными, но менее активными, чем матери социально адаптированных подростков. Кроме того, различия в показателях Я-реальное и Я-идеальное по факторам Оценка и Сила в группе матерей делинквентных подростков больше, чем в сопоставляемой группе. Это может свидетельствовать о неудовлетво- 
ренности различными аспектами своей личности и поведения в группе матерей подростков с делинквентным поведением.

При исследовании особенностей восприятия собственного ребенка-подростка женщиной, три основных фактора восприятия ребенка в реальности (Оценка, Сила, Активность) соотносились с представлениями матерей об образе идеального ребенка (таблица 2).

Из таблицы 2 видно, что в сопоставляемых группах обнаружены статистические различия на высоком уровне значимости по факторам Оценки и Силы восприятия Ребенка в реальности и различия на уровне статистической тенденции по фактору Активности Ребенка-идеального. Матери делинквентных подростков воспринимают их личность как менее положительную и сильную, но более активную, чем матери подростков с нормативным поведением воспринимают личность своих детей. При этом матери делинквентных подростков в идеале хотели бы видеть своего ребенка более положительным, сильным, но менее активным (различия на высоком уровне статистической значимости). Таким образом, можно говорить о том, что матери подростков с делинквентным поведением более критичны в восприятии своих детей, желают значительных изменений в их личности, что, возможно, ведет к предъявлению завышенных требований и усугубляет конфликтную ситуацию в семье.

Результаты эксперимента «Совместное рисование» матерей и их детей-подростков показали, что в диадах «мать - делинквентный подросток» по сравнению с диадами «мать - социально адаптированный подросток» при выполнении совместного рисунка чаще спорят о последовательности работы $(50,0 \%$ и $1,3 \%$ соответственно; $\mathrm{p}<0,001)$, нарушают правила $(98,7 \%$ и $7,8 \%$ соответственно; $\mathrm{p}<0,001), \quad$ не поддерживают контакт глаз $(35,5 \%$ и $0 \%$ соответственно; $\mathrm{p}<0,001)$, рисуют изолированные изображения, не объединенные общей тематикой $(38,2 \%$ и $1,3 \%$ соответственно; $\mathrm{p}<0,001)$ или рисуют каждый на свою тему $(52,6 \%$ и $1,3 \%$ соответственно; $\mathrm{p}<0,001)$, оставляют большую часть листа пустой $(30,3 \%$ и $5,3 \%$ соответственно; $\mathrm{p}<0,001)$, не удовлетворены результатом $(96,1 \%$ и $5,2 \%$ соответственно; $\mathrm{p}<0,001)$ и не могут (отказываются) рассказать о рисунке (31,6\% и 0\% соответственно; $\mathrm{p}<0,001)$.

Анализ совместного рисования матерей и их детей-подростков, дифференцированных по половому признаку, свидетельствует об усилении общегрупповых тенденций в диадах «мать-делинквентная дочь». В них по сравнению с диадами «мать - социально адаптированная дочь» при выполнении совместного рисунка чаще спорят о последовательности работы $(57,1 \%$ и $2,3 \%$ соответственно; $\mathrm{p}<0,001)$, нарушают правила $(100 \%$ и 7,8\% соответственно; $\mathbf{p}<0,001)$, рисуют изолированные изображения, не объединенные общей тематикой $(53,6 \%$ и 2,6\% соответственно; $\mathrm{p}<0,001)$ или рисуют каждая на свою тему $(75,0 \%$ и 2,6\% соответственно; $\mathrm{p}<0,001)$.

Таким образом, нарушения детско-родительских отношений в системе «мать-делинквентный подросток» при взаимодействии в процессе совместного рисования проявляются в неумении и (или) нежелании договариваться, понимать и учитывать интересы друг друга (когнитивный уровень), соблюдать правила (поведенческий уровень), поддерживать эмоциональный контакт, получать удовлетворение от совместной деятельности (эмоциональный уровень).

Результаты настоящего исследования позволили определить мишени психотерапии при работе с матерью делинквентного подростка, которые можно разделить на два блока.

Индивидуальная поддерживающая психотерапия.

1.1. Установление и развитие психологического контакта с матерью делинквентного подростка путем снижения эмоционального напряжения (признание права родителя на ошибку, на негативные чувства; уважение к взглядам родителя; не осуждающие вопросы), которое является источником сопротивления психологической работе.

1.2. Формирование умения распознавать возникновение и усиление нервно-психического напряжения, предупреждать эксплозивные реакции. Обучение адекватным способам эмоциональной разрядки для гармонизации внутреннего состояния.

1.3. Стимулирование позитивного самовосприятия и позитивной самооценки, самопринятия. Формирование адекватного (достижимого) образа Я-идеального путем постановки реалистичных целей саморазвития и самосовершенствования.

1.4. Формирование способности управлять ситуацией (обдумывать решения, планировать время, контролировать реализацию плана, вносить коррективы) и принимать ответственность - прогнозировать результаты своих действий - за события семейной жизни, трудовой деятельности и возможные неудачи.

Вместе с этим, по мере необходимости, следует оказать медицинскую помощь для лечения имеющихся соматических и нервно-психических расстройств, а также социальную поддержку для обеспечения удовлетворительной трудовой занятости, возможно, с привлечением профориентации и дополнительной профессиональной подготовки. Это позволит улучшить не только общее 
психофизическое состояние женщины, но и повысить качество жизни семьи в целом.

Семейная психотерапия.

2.1. Системный анализ диадических подсистем привязанности в родительско-прародительских отношениях с соотнесением их с актуальными детско-родительскими отношениями в особенностях общения, правил и границ дозволенного, степени доверия, способов поощрений, поддержки и наказаний, взаимопонимания ожиданий. Построение системы семейной поддержки матери.

2.2. Коррекция детско-родительских отношений матери и делинквентного подростка на когнитивном, эмоциональном и поведенческом уровнях. На когнитивном уровне - осознание матерью связей между собственной личностью и личностью ребенка, а также между собственными действиями и поведением ребенка; прояснение ожиданий матери и подростка о поведении и действиях друг друга. На эмоциональном уровне - формирование умения оказывать поддержку подростку (через развитие эмпатии, чуткости, внимательности к ребенку, тактичности и прогностичности в общении с ним), позитивного участия и интереса к тому, чем занимается ребенок, каковы его планы. На поведенческом уровне формирование новых конструктивных форм социально-ролевого родительского поведения и реагирования в том числе, в конфликтных ситуациях (родительский тренинг), умения удерживать последовательную воспитательную позицию в вопросах требований и контроля, находить совместные занятия с подростком, удовлетворяющие общим интересам.

\section{ЛИТЕРАТУРА}

1. Бартол $K$. Психология криминального поведения. - 7-е междунар. изд.: пер. с англ. - СПб. : Прайм-ЕВРОЗНАК, 2004. - 352 с.

2. Беличева С.А. Превентивная психология в подготовке социальных педагогов и психосоциальных работников: Учебное пособие - СПб. : Питер, 2012. - $336 \mathrm{c}$.

3. Беляева С.И. Проблемы материнства как психогенный фактор возникновения делинквентного поведения / Девиантное и делинквентное поведение детей и подростков: монография // Под общ. ред. Н. В. Лалетина - Красноярск : Центр информации, 2012. - C. 75-91.

4. Варга А.Я. Системная семейная психотерапия: Краткий лекционный курс. - СПб. : Речь, 2001. $142 \mathrm{c}$.

5. Захаров А.И. Предупреждение отклонений в поведении ребенка. - 3-е изд., испр. - СПб. : Союз: Лениздат, 2000. - 222 с.

6. Королев В.В. Психические отклонения у подростков-правонарушителей - М. : Медицина, 1992. $206 \mathrm{c}$.
7. Личко A.E. Психопатии и акцентуации характера у подростков: патохарактерологический диагностический опросник для подростков (ПДО) - СПб. : Речь, 2013. - 256 с.

8. Личностный дифференциал: методические рекомендации / определения уровня субъективного контроля (УСК): методические рекомендации / НИПНИ им. В.М. Бехтерева; сост.: Е.Ф. Бажин, А.М. Эткинд. - Л., 1983. - 24 с.

9. Лысков Б.Д., Курбатова Т.Н. Понятие о личности преступника / Юридическая психология / сост. и общ. ред. Т.Н. Курбатовой. - СПб. : Питер, 2001. C. $74-91$.

10. Малкова E.E. Тревожность и развитие личности СПб. : Изд-во РГПУ им. А.И. Герцена, 2013. $268 \mathrm{c}$.

11. Методика определения уровня субъективного контроля (УСК): методические рекомендации / НИПНИ им. В.М. Бехтерева; Упр. по внедрению новых лекарств. средств и мед. техники МЗ РФ; сост.: Е.Ф. Бажин, Е.А. Голынкина, А.М. Эткинд. M., 1984. - 22 c.

12. Москвичева Н.Л., Реан А.А. Подросток и семья / Психология подростка. Полное руководство / под общ. ред. А. А. Реана. - СПб. : Прайм-ЕВРОЗНАК, 2008. - C. 203-233.

13. Мясищев В.Н. Психология отношений / под ред. А.А. Бодалева. - М. : МПСИ; Воронеж : НПО «МОДЭК», 2003. - $400 \mathrm{c.}$

14. Pammер M. Помощь трудным детям: пер. с англ. М. : Апрель Пресс, Изд-во ЭКСМО - Пресс, 1999. - $430 \mathrm{c}$.

15. Реан А.А. Характерологические особенности подростков-делинквентов / Вопросы психологии. 1991. - № 4. - С. 139-144.

16. Смит Г. Техника совместного рисования: пер. с англ. / Игровая семейная психотерапия / под ред. Ч. Шеффера, Л. Кери. - СПб. : Питер, 2001. C. $105-112$.

17. Соколова E.T., Николаева В.В. Особенности личности при пограничных расстройствах и соматических заболеваниях. Учебное пособие - M., SvRАргус, 1995. - 359 c.

18. Boswell G. Violent Children and Adolescents: Asking the Question Why - Hoboken, New Jersey: WileyBlackwell, 2000. - 230 p.

19. Bynau C. Accueillir les adolescents en grande difficulté. L'avenir d'une désillusion - Ramonville Saint-Agne : Eitions érés, 2004. - 319 p.

20. DeLisi M., Beaver K.M. Criminological Theory: A Life-Course Approach - Burlington: Jones \& Bartlett Learning, 2012. - 334 p.

21. Dreikurs R., Soltz V. Children: the Challenge - New York City : Plume, 1992. - 335 p.

22. Erikson E.H. Jugend und Krise: Die Psychodynamik im sozialen Wandel - Stuttgart : Klett-Cotta, 2003. $344 \mathrm{p}$.

23. Gorman-Smith D., Schoeny M. Contextual influences on adolescent risk behaviour: Community [Электронный pecypc] // University of Illinois at Chicago. - Режим доступа: http://www.pubfacts.com/author/ Deborah+Gorman-

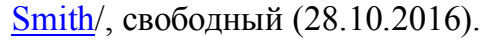


24. Hayman L.L., Mahon M.M., Turner J.R. Health and Behavior in Childhood and Adolescence. - New York : Springer Publishing, 2002. - 304 p.

25. Henggeler S.W., Cunningham P.B., Schoenwald S.K. Multisystemic Therapy for Antisocial Behavior in Children and Adolescents - New York City: The Guilford Press, 2009. - 324 p.

26. Patterson G.R., DeBaryshe B.D., Ramsey E.A developmental perspective on antisocial behavior /
American Psychologist - 1989. - Vol. 44, N 2. P. 329-335.

27. Retzlaff $R$. Einführung in die systemische Therapie mit Kindern und Judendlichen - Heidelberg : Carl-AuerVerlag, 2013. - $120 \mathrm{p}$.

28. Thio A.D. Taylor J.D., Schwartz M.D. Deviant Behavior - London : Pearson, 2012. - 496 p. 